Hall-Asheshov, E. \& Asheshov, I. N. (1956). J. gen. Microbiol. 14, 174-187

\title{
The Induction of the Lytic Cycle in Lysogenic Bacteria by Phagolessin A 58
}

\author{
By ELIZABETH HALL-ASHESHOV AND I. N. ASHESHOV \\ The Lister Institute of Preventive Medicine, London
}

\begin{abstract}
SUMMARY: Phagolessin A58, an antibiotic having antiphage activity, was found to have an action which induced the lytic cycle in some strains of lysogenic bacteria. Four different lysogenic organisms were tested: Bacillus megaterium 899 ; Escherichia coli $\mathrm{FCb} ; \boldsymbol{E}$. coli Temple; E. coli Lampert. Two of the organisms were induced by phagolessin A58 and two were not. There appeared to be a relationship between the susceptibility of a given strain to induction by ultraviolet irradiation and to induction by phagolessin A58. The four different phages carried by the respective lysogenic strains were inactivated to a greater or lesser extent by phagolessin A58, but there was no correlation between such sensitivity on the part of the carried phage and inducibility of the particular lysogenic strain. Serial transfers of the four lysogenic strains in broth containing phagolessin A58 were made in an attempt to produce non-lysogenic, phage-sensitive mutants. With only one organism, Bacillus megaterium 899 , did this treatment result in the selection of such a mutant.
\end{abstract}

Some of the chemical and biological properties of phagolessin A58 were described in previous publications (Asheshov, Strelitz \& Hall, 1952; Hall \& Asheshov, 1953), where it was shown that it caused an apparently irreversible inactivation of free phage particles after a relatively short contact. Not all of the phage strains tested were sensitive to its action, some 10 out of 60 strains being completely resistant. The phagicidal action could be blocked by the addition of deoxyribose nucleic acid. The present investigation was undertaken to determine whether phagolessin A58 could also inactivate the intracellular phage carried by lysogenic bacteria-the 'prophage' of Lwoff (Lwoff \& Gutmann, 1950)-and, in effect, 'cure' lysogenic cells. It was found that the main action of phagolessin A58 on lysogenic systems was an inducing onei.e. it caused lysogenic cells to enter the lytic cycle, lyse and release their phage.

\section{METHODS}

Phagolessin A58: The preparations of phagolessin A58 used throughout this investigation were methanol solutions of lyophilized concentrates and contained small amounts of impurities. Concentrations, expressed as dilution units $/ \mathrm{ml}$, were based on the results of weekly serial dilutions against cholera phage $\mathrm{C}$, the phage chosen as standard for this antibiotic.

Media. Nutrient broth was prepared as follows: papain-digest of horse meat (Asheshov, 1941), $400 \mathrm{ml}$.; yeast extract (Difco), $2.5 \mathrm{~g}$; trace element solution, $1 \mathrm{ml}$; tap water, $600 \mathrm{ml}$. The $\mathrm{pH}$ value was adjusted to $\mathbf{7 \cdot 2}$.

Solid medium was prepared by adding $7 \cdot 5 \mathrm{~g}$. New Zealand agar (Davis) to 11 . of nutrient broth. 
Streptomycin plates, used in some experiments, were prepared as above, with the further addition of 1000 units of streptomycin $/ \mathrm{ml}$.

Buffers. Phosphate buffer: a concentrated solution containing $87 \mathrm{~g}$. $\mathrm{Na}_{2} \mathrm{HPO}_{4}$ (anhydrous Sorensen) and $53 \mathrm{~g} . \mathrm{KH}_{2} \mathrm{PO}_{4}$ (anhydrous Sorensen)/l. distilled water was used to prepare solutions as follows. M/15 buffer for UV radiation experiments; the concentrated buffer solution was diluted 1/15 in distilled water. $\mathrm{NaCl}$ was added to a final concentration of $0.5 \%(\mathrm{w} / \mathrm{v})$ and $\mathrm{MgSO}_{4}$ to a final concentration of $\mathbf{M}^{-3}$. For $\mathrm{m} / 50$ buffer the concentrated buffer solution was diluted $1 / 50$ in distilled water. Unless otherwise noted, there was no further addition. In all cases the final $\mathrm{pH}$ value was adjusted to $7 \cdot 0$.

Lysogenic cultures and indicator strains. Four different lysogenic cultures were studied. They were Bacillus megaterium strain 899 , first described by Den Dooren de Jong (1930), and three lysogenic strains of Escherichia coliFCb, Temple and Lampert. The culture of Bacillus megaterium 899 and its indicator strain, B. megaterium PR3E, were kindly supplied by Professor P. B. Cowles. Escherichia coli FCb was obtained from Dr N. A. Boulgakov, E. coli Temple from Dr M. Rakieten. E. coli Lampert was one of the host strains in the J. Ward MacNeil collection. The indicator strain used with E. coli $\mathbf{F C b}$ was Shigella dysenteriae Y $6 \mathrm{R}$ : a strain of $S$. flexneri var. Newcastle was used as indicator for $\boldsymbol{E}$. coli Temple and $\boldsymbol{E}$. coli Lampert. All cultures were maintained on agar slants at $10^{\circ}$.

Production of cell-free phage filtrates. The techniques used varied with the lysogenic strain. With Bacillus megaterium 899 and Escherichia coli Lampert, high titre stocks were best obtained by filtering a $24 \mathrm{hr}$. broth culture of the lysogenic strain. When this procedure was used with $E$. coli Temple or $\boldsymbol{E}$. coli FCb, the titres of the filtrates were rather low, and better results were obtained by growing the phage on the appropriate indicator strains. Pyrex sintered glass filters (UF) were used as a routine. Phage filtrates were stored at $10^{\circ}$. They were all rather unstable and it was necessary to prepare fresh filtrates at frequent intervals. The phages carried by the four lysogenic strains will be referred to by the name of the strain carrying them: $899, \mathrm{FCb}$, Temple, Lampert.

Use of streptomycin-resistant indicator strains in assaying phage. Bertani (1951) described a technique for assaying phage in a mixture of lysogenic cells and free phage which proved useful in the present study. According to this method, assays for free phage particles are made on streptomycin plates inoculated with a streptomycin-resistant mutant of the indicator strain. Lysogenic organisms are inhibited by the streptomycin and so do not form colonies; clearings produced by free phage particles can then be seen easily. This method was used in assaying free phage in the three lysogenic strains of Escherichia coli where, under normal conditions of growth, the cell concentration greatly exceeded the free phage concentration. It was not found necessary to use this method in assaying free phage in cultures of Bacillus megaterium 899 since, in this culture, the free phage concentration was higher than the cell concentration. The phages carried by the three lysogenic strains of Escherichia 
coli were resistant to the concentration of streptomycin used, and free phage particles plated equally well on plain or on streptomycin plates. The three phages also showed the same efficiency of plating on plain agar regardless of whether they were plated on the streptomycin-sensitive parent strain or on the streptomycin-resistant mutant of the indicator strain.

Method used in assaying bacteria and phage. The loop dilution method of Asheshov \& Heagy (1951) was used in assaying bacteria and phage. Phage assays were made on plates previously flooded with the appropriate indicator strain. All counts represent the mean of duplicate platings.

Ultraviolet radiation. Lwoff, Simonovitch \& Kjeldgaard (1950) discovered that a relatively short exposure to ultraviolet (UV) radiation induced some lysogenic cultures to enter the lytic cycle and, after a definite latent period, to lyse and release a normal burst of newly formed phage particles. The technique used in the present study was as follows. Actively growing organisms in nutrient broth were centrifuged down, washed to remove free phage particles, and resuspended in $\mathbf{M} / \mathbf{1 5}$ phosphate buffer. Five ml. of the buffer suspension were placed in a sterile Petri dish and irradiated for varying periods of time. Following irradiation the organisms were diluted 1/10,000 in nutrient broth and incubated at $37^{\circ}$. After 30-45 min. of incubation, platings were made to count colony-formers and clearing-producers. The UV source was a high-pressure mercury arc lamp, and irradiation was done at a distance of $40 \mathrm{~cm}$., the intensity of irradiation at this distance being such that phage $\mathrm{T} 2$ was $99 \%$ inactivated after 7 sec. of exposure.

\section{RESULTS}

\section{Characteristics of the four lysogenic organisms}

Bacillus megaterium 899. This culture has been described in detail by a number of workers, therefore only a brief summary of our results will be given here. The multiplication of organisms and production of phage during growth in nutrient broth at $35^{\circ}$ is represented in Fig. 1. During the period of exponential multiplication of bacilli the phage production ran approximately parallel, with a constant ratio of phage to organisms of 6:1. Free phage particles of phage 899 were readsorbed by the lysogenic bacilli and a proportion was therefore 'lost' as infective centres (Lwoff \& Gutmann, 1950).

Irradiation of the culture by UV light causes induction with lysis of the cells and release of free phage particles (Lwoff et al. 1950). The amount of induction obtained by the technique described above is expressed as a function of UV dose in Fig. 2. Maximum induction was produced after exposure for $60 \mathrm{sec}$. Induced cells began to lyse $65 \mathrm{~min}$. after irradiation, with release of c. 100 phage particles/induced organism.

When non-induced organisms of this culture were plated on the indicator strain, each organism gave rise to a colony which was surrounded by a zone of lysis. Induced organisms, on the other hand, produced clearings on the indicator strain which were identical with those produced by free phage particles.

Escherichia coli $\mathbf{F C b}$. The multiplication of organisms and production of free 
phage by this culture, grown in nutrient broth at $35^{\circ}$, is shown in Fig. 3. Free phage increased logarithmically at a rate equal to that of the organisms, with a constant ratio of free phage to cells of $1: 100$. Free phage particles were not adsorbed by lysogenic organisms at an appreciable rate.

This culture could be induced by UV radiation. In Fig. 4, the amount of induction is plotted as a function of UV dose. Maximum induction was obtained after exposure for 10-15 sec. Induced organisms began to lyse 120$130 \mathrm{~min}$. after irradiation, and the average burst size was approximately $\mathbf{2 5 0}$ phage particles/induced organism.

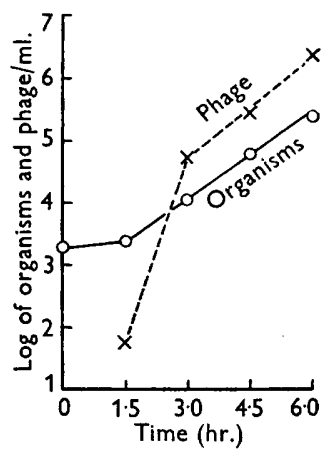

Fig. 1

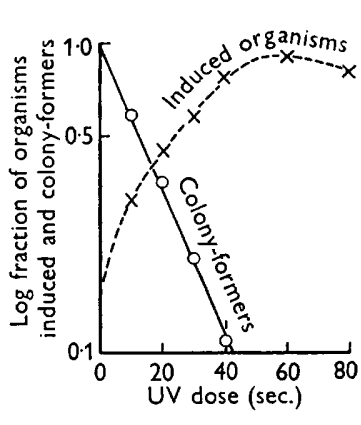

Fig. 2

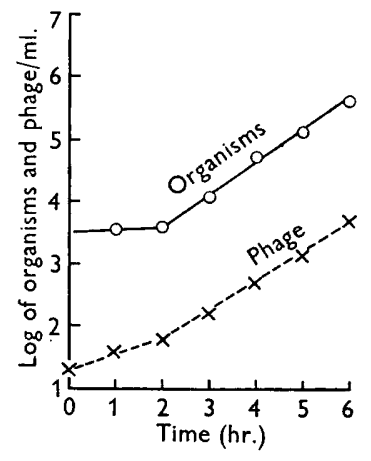

Fig. 3

Fig. 1. Multiplication of organisms and production of phage by lysogenic Bacillus megaterium 899 in nutrient broth at $35^{\circ}$.

Fig. 2. Induction of lysogenic Bacillus megaterium 899 by UV radiation, expressed as a function of dosage. The log of the fraction of colony-formers and organisms induced is plotted against UV dose (sec.)

Fig. 3. Multiplication of organisms and production of phage in lysogenic Escherichia coli FCb in nutrient broth at $35^{\circ}$.

When non-induced organisms of this culture were plated on the indicator strain, less than $1 \%$ gave rise to colonies surrounded by a very narrow zone of lysis, the majority showed no evidence of lysogenicity. Induced organisms failed to form a colony and produced clearings on the indicator strain. Clearings produced by free phage particles of phage FCb were clear-cut and did not show any resistant growth, and there was considerable variation in the size of the clearings. On the other hand, clearings produced by UV-induced organisms before lysis were larger and more regular in size and outline than those which developed from free phage particles. Similar results were reported by Weigle \& Delbrück (1951) for the lysogenic strain of Escherichia coli, K-12.

Escherichia coli Temple. Under normal conditions of growth very few organisms of $\boldsymbol{E}$. coli Temple appeared to undergo spontaneous lysis. The growth curve and the free phage concentration are shown in Fig. 5. Nutrient broth was the medium used in this experiment and incubation was at $35^{\circ}$. Phage production ran parallel to multiplication of organisms, with a constant ratio of phage to organisms of 1:300. E. coli Temple was not induced by 
exposure to UV radiation. Such treatment resulted in a loss of viable organisms at an exponential rate without any release of phage (Fig. 6).

Organisms of this culture, plated on the indicator strain, gave no evidence of lysogenicity. Clearings of free particles of phage Temple were of medium size with irregular edges and showed a central area of secondary growth which was found to consist of the indicator strain lysogenized by phage Temple. Free particles of phage Temple were not adsorbed by the lysogenic cells at a measurable rate.

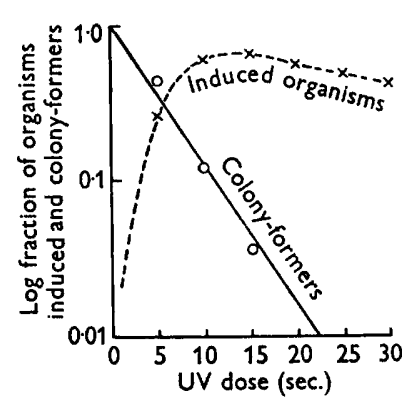

Fig. 4

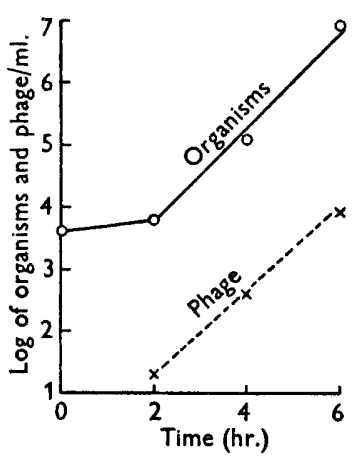

Fig. 5

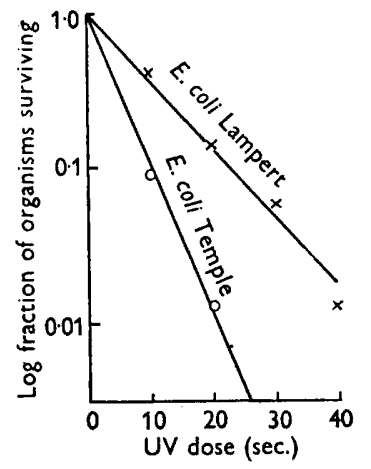

Fig. 6

Fig. 4. Induction of Escherichia coli $\mathrm{FCb}$ by UV radiation expressed as a function of dosage. The log of the fraction of colony-formers and organisms induced is plotted against UV dose (sec.).

Fig. 5. Multiplication of organisms and production of phage by lysogenic Escherichia coli Temple in nutrient broth at $35^{\circ}$.

Fig. 6. Inactivation of Escherichia coli strains Temple and Lampert following UV radiation. There were no induced organisms. The $\log$ of the fraction of cells able to form colonies is plotted against UV dose (sec.).

Escherichia coli Lampert. This culture resembled $\boldsymbol{E}$. coli Temple in a number of respects. The amount of free phage released into the medium during growth in nutrient broth at $35^{\circ}$ was very small (Fig. 7). It was characteristic of this culture that phage production ran parallel to multiplication of organisms only at the beginning of the logarithmic growth phase. At that time the ratio of phage particles to organisms was approximately 1:500. Subsequently very little free phage was produced. Experiments showed that phage Lampert was not adsorbed by lysogenic organisms at a measurable rate, so that the low concentration of free phage particles during the latter part of the growth curve could not be accounted for by assuming that the free phage particles were being readsorbed on to lysogenic organisms and so lost. The results, therefore, suggests that the probability of an organism undergoing spontaneous lysis is greater during the early part of the logarithmic growth phase than at any other time during the growth period.

The culture was not inducible by UV radiation, the only effect of such treatment being an inactivation of viable organisms without any release of active phage (Fig. 6). 
Escherichia coli Lampert plated on the indicator strain showed no evidence of lysogenicity. Clearings of phage Lampert were extremely small and were quite clear and apparently free from resistant growth.

\section{Action of phagolessin A58 on free phage particles}

Free particles of the four carried phages were inactivated to a greater or lesser extent following exposure to phagolessin A58. The rate of inactivation of each phage was studied over a period of time at one concentration of the

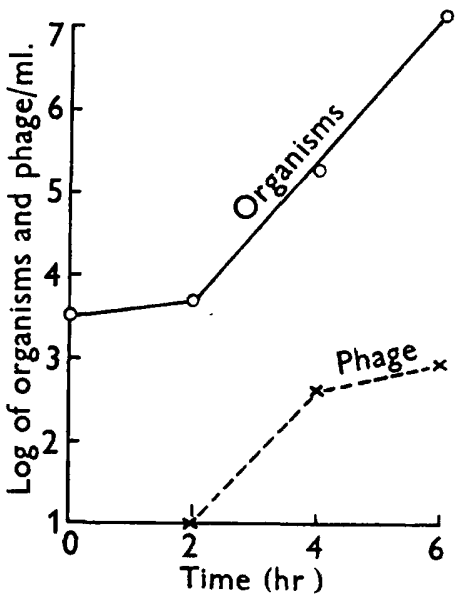

Fig. 7

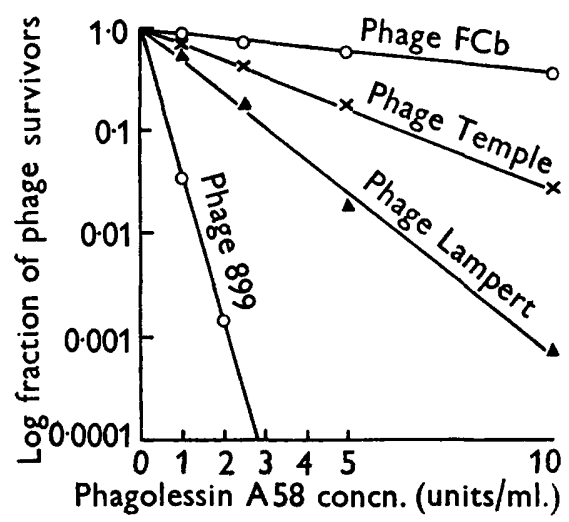

Fig. 8

Fig. 7. Multiplication of organisms and production of phage in lysogenic Escherichia coli Lampert in nutrient broth at $35^{\circ}$.

Fig. 8. Inactivation of the four phages $(899, \mathrm{FCb}$, Temple, Lampert) by exposure to different concentrations of phagolessin A 58. Each phage was diluted in nutrient broth and mixed with varying concentrations of antibiotic at $35^{\circ}$ for $10 \mathrm{~min}$. Following this they were rapidly diluted and plated to count survivors. The log of the fraction of survivors is plotted against antibiotic concentration (units/ml.).

antibiotic. In these experiments the suspending medium was nutrient broth and inactivation was carried out at $35^{\circ}$. The rate of inactivation was exponential with velocity constants per min. at $1 \mathrm{unit} / \mathrm{ml}$. of phagolessin A58 of 0.14 for phage $899,0.0048$ for phage $\mathrm{FCb}, 0.016$ for phage Temple, 0.030 for phage Lampert. The rate of inactivation varied directly with the concentration of phagolessin A58 used (Fig. 8).

\section{Action of phagolessin A58 on lysogenic cells}

The majority of experiments were conducted with Escherichia coli FCb, and only these results will be reported in any detail. $\boldsymbol{E}$. coli $\mathrm{FCb}$ was exposed to varying concentrations of phagolessin A58 in nutrient broth at $37^{\circ}$. The starting inoculum, which consisted of $c .4 \times 10^{3} \mathrm{organisms} / \mathrm{ml}$., was prepared by diluting a suspension of organisms from an $18 \mathrm{hr}$. agar slope. The cells were in the lag phase of growth. Three different concentrations of phagolessin A58 were used $(10,20$ and 30 units $/ \mathrm{ml}$.) and colony counts and phage counts were made 
at hourly intervals for $3 \mathrm{hr}$. Phage counts were made on both plain and on streptomycin plates, both inoculated with the streptomycin-resistant mutant of the indicator strain. The results are summarized in Table 1.

\section{Table 1. Effect of phagolessin A58 on cell growth and phage production in Escherichia coli $\mathrm{FCb}$}

Organisms in nutrient broth at $37^{\circ}$, were exposed to $0,10,20$ and 30 units phagolessin A58/ml. Counts of colony-formers and clearings were made at hourly intervals for $3 \mathrm{hr}$. Phage counts were made on plain and streptomycin agar, both inoculated with the streptomycin-resistant mutant of the indicator strain.

\begin{tabular}{|c|c|c|c|c|}
\hline \multirow[b]{2}{*}{$\begin{array}{c}\text { Period of } \\
\text { incubation } \\
\text { (hr.) }\end{array}$} & \multirow[b]{2}{*}{$\begin{array}{c}\text { Concn. of } \\
\text { A } 58 \\
\text { (units/ml.) }\end{array}$} & \multirow[b]{2}{*}{$\begin{array}{l}\text { Colony count } \\
\text { (no. } / \mathrm{ml}_{i} \text { ) }\end{array}$} & \multicolumn{2}{|c|}{$\begin{array}{l}\text { Phage count } \\
\text { (clearings/ml.) }\end{array}$} \\
\hline & & & Plain agar & $\begin{array}{l}\text { Streptomycin } \\
\text { agar }\end{array}$ \\
\hline 1 & $\begin{array}{r}0 \\
10 \\
20 \\
30\end{array}$ & $\begin{array}{l}4.6 \times 10^{3} \\
3.4 \times 10^{3} \\
1.5 \times 10^{3} \\
4.8 \times 10^{2}\end{array}$ & $\begin{array}{l}2.0 \times 10^{1} \\
1.6 \times 10^{2} \\
1.4 \times 10^{3} \\
1.9 \times 10^{3}\end{array}$ & $\begin{array}{r}2.0 \times 10^{1} \\
<2.0 \times 10^{1} \\
<2.0 \times 10^{1} \\
<2.0 \times 10^{1}\end{array}$ \\
\hline 2 & $\begin{array}{r}0 \\
10 \\
20 \\
30\end{array}$ & $\begin{array}{r}5 \cdot 0 \times 10^{3} \\
2 \cdot 1 \times 10^{3} \\
2 \cdot 6 \times 10^{2} \\
<2.0 \times 10^{1}\end{array}$ & $\begin{array}{l}2.0 \times 10^{1} \\
1.2 \times 10^{3} \\
1.9 \times 10^{3} \\
2.2 \times 10^{3}\end{array}$ & $\begin{array}{r}2.0 \times 10^{1} \\
<2.0 \times 10^{1} \\
<2.0 \times 10^{1} \\
<2.0 \times 10^{1}\end{array}$ \\
\hline 3 & $\begin{array}{r}0 \\
10 \\
20 \\
30\end{array}$ & $\begin{array}{r}6.6 \times 10^{3} \\
1.0 \times 10^{3} \\
<2.0 \times 10^{1} \\
<2.0 \times 10^{1}\end{array}$ & $\begin{array}{l}8.0 \times 10^{1} \\
8.8 \times 10^{2} \\
1.7 \times 10^{3} \\
1 \cdot 2 \times 10^{3}\end{array}$ & $\begin{array}{r}8.0 \times 10^{1} \\
<2.0 \times 10^{1} \\
<2.0 \times 10^{1} \\
<2.0 \times 10^{1}\end{array}$ \\
\hline
\end{tabular}

Judging by the loss in colony-formers in those tubes which contained phagolessin A58, the antibiotic appeared to exert a strong bactericidal action. The marked increase in phage concentration caused by the antibiotic suggested, however, that the action was an inducing one-i.e. that lysogenic cells were being induced to enter the lytic cycle, and after a period of intracellular phage growth, to lyse and release their phage. Several observations showed that phage clearings which were present on plain plates but not on streptomycin plates were due, not to free phage particles, but to induced organisms which were intact at the time of plating but which lysed after plating and so did not form a colony. In the first place, phage $\mathrm{FCb}$ is fairly sensitive to inactivation by phagolessin A58 and one would expect few, if any, of the free phage particles to survive any of the three concentrations used. In the second place, the clearings were larger and more regular in size and shape than was usually the case with free phage particles. They resembled the clearings produced by UVinduced cells. Also, the discrepancy between the phage counts depending on whether platings were made on plain or on streptomycin plates was added evidence that such clearings did not arise from free phage particles. Free phage particles plate equally well on plain or on streptomycin plates, and it seemed probable that induced organisms would be inhibited by streptomycin and would fail to lyse and release their phage.

As a test of the hypothesis that organisms in which induction had been initiated by phagolessin A58, were, in fact, inhibited by streptomycin, it was 
decided to see whether the latter had a similar offset on organisms induced by UV radiation. Escherichia coli $\mathrm{FCb}$ was irradiated in buffer for 15 sec., diluted into broth and incubated at $37^{\circ}$. Phage counts were made at intervals on plain and on streptomycin plates. The results, presented in Fig. 9, showed that up to $90 \mathrm{~min}$. after induction (c. three-quarters of the latent period) induced organisms were unable to produce clearings in the presence of streptomycin. After $90 \mathrm{~min}$. the number of organisms which produced clearings increased rapidly until, at $120 \mathrm{~min}$., when lysis began, virtually all of the induced organisms produced clearings on the streptomycin plates. There is, therefore, a 'streptomycin-sensitive' phase followed by a 'streptomycinresistant' phase. It is possible that the phase of streptomycin-resistance is correlated with the appearance of mature phage particles inside the cell. On the basis of these results we concluded that the action phagolessin A58 on $E$. coli $\mathrm{FCb}$ is not a direct bactericidal one but an inducing one.

\section{Induction of Escherichia coli $F C b$ by phagolessin $A 58$}

In order to demonstrate induction more clearly a technique was adopted similar to that described by Williams Smith (1953) for demonstrating induction of lysogenic Salmonella strains by nitrogen mustard. Suspensions of Escherichia coli $\mathbf{F C b}$ in the exponential growth phase were centrifuged, washed free of phage particles and resuspended in $\mathrm{m} / \mathbf{5 0}$ phosphate buffer. The suspension was divided into two parts and 15 units phagolessin A58/ml. were added to one part, the other serving as a control. The suspensions were incubated at $37^{\circ}$, and at regular intervals samples were removed, diluted $1 / 20,000$ in nutrient broth and plated to count colony-formers and induced organisms. Fig. 10 shows the results of such an experiment where the fraction of colony-formers and induced organisms is plotted as a function of time of exposure to phagolessin A58. The picture is similar to that obtained with UV induction (Fig. 4) and shows that maximum induction occurred between 15 and $30 \mathrm{~min}$.

In an extension of this experiment, organisms, induced by exposure to 15 units phagolessin A58/ml. for 20 min., were diluted in nutrient broth, incubated at $37^{\circ}$, and plated at regular intervals in order to determine the length of the latent period and the average burst size/induced organism. Lysis began 90-100 min. after induction, with an average burst size of c. 200-250 phage particles/induced organism. Organisms induced by phagolessin A58, therefore, had the same average burst size as UV-induced organisms, but the organisms lysed some $30 \mathrm{~min}$. earlier than UV-induced organisms. These results are in agreement with other cases reported in the literature, when organisms induced by agents other than UV irradiation, showed a shorter latent period than UV-induced organisms (Jacob, 1954).

\section{Effect of deoxyribose nucleic acid $(D N A)$ on the inducing action of phagolessin $A 58$}

It was reported in an earlier publication (Asheshov et al. 1952) that the inactivation of free phage particles by phagolessin A58 was inhibited by DNA. DNA also inhibited the inducing action of phagolessin A58. The usual 
procedure in these experiments was to add DNA to the solution of antibiotic to give a final DNA concentration of $0.01 \%(w / v)$. When such mixtures were added to lysogenic Escherichia coli FCb organisms, no induction occurred. When the DNA was added after induction had begun it prevented any further induction but was unable to affect cells which were already induced at the time of its addition.

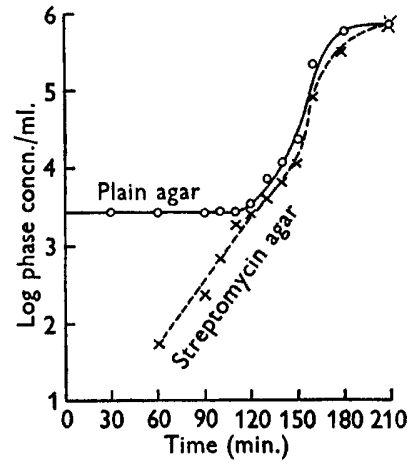

Fig. 9

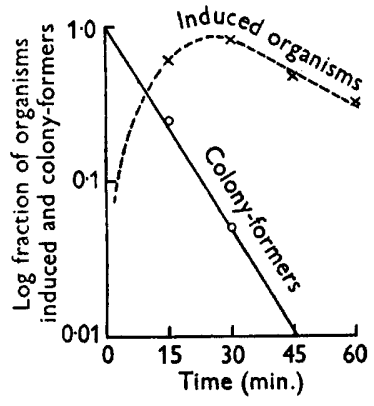

Fig. 10

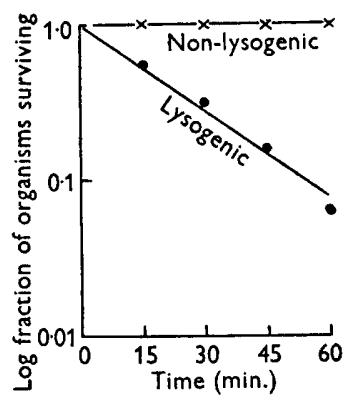

Fig. 11

Fig. 9. Effect of streptomycin on UV-induced Escherichia coli FCb. Organisms, induced by exposure to UV radiation for 15 sec. were diluted in nutrient broth and incubated at $37^{\circ}$. At regular intervals platings were made on plain and on streptomycin agar plates to count clearings. The log of the phage concentration $/ \mathrm{ml}$. is plotted against the time after irradiation. $0 \mathrm{hr} .=$ time of dilution in nutrient broth.

Fig. 10. Induction of Escherichia coli $\mathrm{FCb}$ by phagolessin A 58, expressed as a function of the time of exposure. The organisms were exposed to 15 units phagolessin $\mathrm{A58} / \mathrm{ml}$. in $\mathbf{M} / \mathbf{5 0}$ phosphate buffer at $37^{\circ}$. At regular intervals samples were removed, diluted in nutrient broth, and plated to count colony-formers and organisms induced. The log of the fraction of colony-formers and organisms induced is plotted against the time of exposure.

Fig. 11. A comparison of the sensitivity to phagolessin A58 of lysogenic Bacillus megaterium 899 and its non-lysogenic mutant. Organisms of each of the two strains, in the log phase of growth, were washed, suspended in $\mathrm{M} / 50$ phosphate buffer and exposed to 15 units phagolessin $\mathbf{A 5 9} / \mathrm{ml}$. at $37^{\circ}$. At $15 \mathrm{~min}$. intervals samples were removed, diluted in nutrient broth and plated to count colony-formers. The log of the fraction of organisms able to form colonies is plotted against time of exposure.

\section{Effect of phagolessin A58 on the other three lysogenic cultures}

Experiments similar to those described above were carried out with the other three lysogenic organisms. Bacillus megaterium 899 was induced by exposure to phagolessin A58 and results similar to those described with UV irradiation were obtained with the exception that the latent period was reduced to $45 \mathrm{~min}$. (i.e. approximately $20 \mathrm{~min}$. shorter than was the case with UV-induced $B$. megaterium 899). Induction was inhibited in the presence of DNA but was not reversed by adding DNA once it was established.

Exposure of Escherichia coli Temple or E. coli Lampert to phagolessin A58 did not cause any apparent induction. There was a loss in colony-formers 
following such treatment but there was no increase in phage titre. We concluded, therefore, that these two lysogenic strains are not inducible by either UV irradiation or by phagolessin A58.

\section{The use of phagolessin A58 to select non-lysogenic mutants}

Phagolessin A58 can be considered to have two separate actions on lysogenic Bacillus megaterium 899 and Escherichia coli $\mathrm{FCb}$, and their carried phages. First, the antibiotic induces the organisms to lyse and release their phage (the inducing action): secondly, the antibiotic inactivates the free particles released by the lysing organisms (the phagicidal action). It seemed that, with these two properties, it should be possible to select non-lysogenic phagesensitive mutants by growing the lysogenic organisms over a period of time in the presence of the antibiotic. The combined inducing and phagicidal actions should provide conditions favourable to the selection of such mutants provided that they arise fairly frequently during the growth of lysogenic organisms. Phage 899 requires calcium ions for some stage in its intracellular development in sensitive organisms (Wahl, 1946). Clarke (1952) produced a non-lysogenic phage-sensitive mutant of Bacillus megaterium 899 after 61 subcultures of the lysogenic culture in calcium-deficient medium. Lwoff (1953) confirmed these results and isolated such a mutant after 25 to 34 cultures. The phagicidal action of phagolessin A58 might be considered to correspond to the effect of calcium deficiency since in both cases non-lysogenic phage-sensitive mutants would be protected from the action of free phage particles. The additional inducing action of phagolessin A58 should further aid in the selection by eliminating lysogenic organisms-i.e. by causing them to lyse. One would expect, therefore, that transfers of $B$. megaterium 899 in the presence of phagolessin A 58 would produce a non-lysogenic phage-sensitive mutant more rapidly than cultivation of the lysogenic organisms in calcium-free medium. In theory it should also be possible to obtain similar results with Escherichia coli $\mathrm{FCb}$ since both the inducing and phagicidal actions would be operating. With the other two lysogenic strains ( $E$. coli Temple and $E$. coli Lampert), which are not inducible, only the phagicidal action should operate.

Accordingly, attempts were made to produce non-lysogenic phage-sensitive mutants of the four lysogenic strains by means of serial subculture in nutrient broth containing phagolessin A58. Two concentrations of phagolessin A58 were used-10 or 20 units $/ \mathrm{ml}$. Fairly large numbers of organisms were transferred each time to give a starting inoculum, at each transfer, of c. $10^{5}$ organisms $/ \mathrm{ml}$, in order to increase the chance of picking up any mutants that might be present. Subcultures were made every $12 \mathrm{hr}$. and the tubes were incubated at $37^{\circ}$.

The subcultures were examined at intervals to see whether the treatment had affected the lysogenicity of the strain. With Bacillus megaterium 899 the method was quite simple. The $12 \mathrm{hr}$. growth of the subculture being tested was centrifuged down and the supernatant fluid assayed for free phage particles. The organisms were resuspended in nutrient broth, and suitable dilutions plated on plain agar plates and on plain agar plates first inoculated with the 
indicator strain. The number of colonies which developed on plain agar gave the total cell concentration, while the number of colonies which were surrounded by the typical lytic zone when plated on the indicator strain gave the total number of lysogenic organisms. A difference between the total count of organisms and the lysogenic organism count indicated that non-lysogenic organisms were present. With this method it was possible to calculate the percentage of non-lysogenic mutants present in any subculture. As a further confirmation, individual colonies were isolated and tested for lysogenicity and sensitivity to phage 899 . This method could not be used with the three lysogenic strains of Escherichia coli since it is not possible to distinguish between lysogenic and non-lysogenic organisms by plating on the appropriate indicator strain. However, by using Bertani's streptomycin technique (Bertani, 1951) it was a simple matter to assay the subcultures for free phage concentration. The $\mathbf{1 2} \mathrm{hr}$. growth was suitably diluted and plated on streptomycin agar plates with the streptomycin-resistant mutant of the indicator strain. The concentration of free phage particles in the treated tubes was compared with that in the untreated control. As an additional check on the lysogenicity of a particular subculture, the growth was plated out and individual colonies, isolated into nutrient broth, were tested for phage production after several hours of incubation at $37^{\circ}$ by the streptomycin technique.

We were successful only with Bacillus megaterium 899 . With this organism it was usually possible to observe the appearance of non-lysogenic mutants after 4 to 5 subcultures. In one experiment, $28 \%$ of the organisms were nonlysogenic in the 4 th subculture, $96 \%$ in the 10th subculture, and the 12th subculture contained no free phage particles and appeared to consist entirely of non-lysogenic organisms. Not all such experiments with this strain were successful, however, and on two occasions subcultivation resulted in a complete sterilization after 4 to 6 subcultures. The non-lysogenic mutants that were isolated were all sensitive to phage 899 , and were also highly resistant to phagolessin A 58. When suspensions of the mutant in $\mathrm{M} / 50$ buffer were exposed to 15 units phagolessin A58/ml. for $1 \mathrm{hr}$. at $37^{\circ}$ there was no decrease in the number of colony-formers. During the same period of time the original lysogenic strain showed a loss of some $93 \%$ of viable organisms as judged by their colony-forming ability (Fig. 11). The non-lysogenic mutant could be re-lysogenized by exposing it to phage 899 , and the re-lysogenized culture showed the same sensitivity to phagolessin A 58 as the original lysogenic strain. It is the presence of the prophage in the lysogenic organism, therefore, which is responsible for the sensitivity of the lysogenic organism to phagolessin A58.

Subcultivation of the three lysogenic strains of Escherichia coli in phagolessin A58 had no effect on the lysogenicity of the organisms. There was some inhibition in growth (particularly with $E$. coli $\mathrm{FCb}$, which was to be expected in view of the inducing action of the antibiotic) but after 26 subcultures the organisms were still fully lysogenic. Moreover, the free phage concentration of the $12 \mathrm{hr}$. growth of the $26 \mathrm{th}$ subcultures was only slightly lower than in the untreated control. This failure with the three $\boldsymbol{E}$. coli strains may be due to several factors. The emergence of a non-lysogenic mutant depends on the 
frequency with which lysogenic organisms mutate to a non-lysogenic form, and it is possible that this mutation occurs less frequently in these three cultures than in Bacillus megaterium 899. Again, the sensitivity of phages FCb, Temple and Lampert to phagolessin A58 is much lower than that of phage 899, so that more free phage would survive to eliminate any non-lysogenic phagesensitive mutants that might be present. Also, phagolessian A58 is very unstable in nutrient broth at $\mathrm{pH} 7.0$ at $37^{\circ}$, about $50 \%$ of its phagicidal action is destroyed after $c .6 \mathrm{hr}$. in nutrient broth under these conditions. These facts probably explain the relatively high concentration of free phage in the treated tubes. It is possible that if subcultivation were made at shorter intervals we might have succeeded with these cultures. Attempts to grow the strains at antibiotic concentrations higher than 20 units $/ \mathrm{ml}$. were tried but were not successful since the cultures were sterilized.

\section{DISCUSSION}

Since the original discovery by Lwoff et al. (1950) that in certain lysogenic strains of bacteria the lytic cycle can be induced by UV irradiation, a number of other inducing agents have been discovered (Lwoff \& Simonovitch, 1952; Lwoff \& Jacob, 1952; Jacob, 1952a; Williams Smith, 1953). In general these inducing agents are also mutagenic or carcinogenic agents. Induction by these other agents resembles that by UV radiation in all except two respects. Organisms induced by UV radiation can be restored to their normal lysogenic state by illumination with visible light (photorestoration), provided that they are illuminated within 20-30 min. after induction (Jacob, 1950). Attempts to restore organisms induced by the other inducing agents by means of visible light have failed. Also, the length of the latent period of UV-induced organisms is 20-30 min. longer than that of similar organisms induced by any of the other agents. Jacob (1954) suggested that these two observations are related, and according to his hypothesis, the prophage in UV-induced organisms requires approximately $\mathbf{2 0 - 3 0} \mathrm{min}$. to pass into the vegetative state, and until the vegetative state has been reached, such organisms are restorable. Similar organisms, induced by agents other than UV radiation, pass immediately into the vegetative state and are, therefore, not restorable, and have a latent period which is shorter than that of UV-induced organisms by c. 20-30 min.

Phagolessin A58 resembles these other inducing agents rather than UV radiation with regard to the restorability of the induced organisms and the length of the latent period. Apart from these two differences there is a parallelism between induction by UV radiation and by phagolessin A 58 in that strains which are inducible by one agent are also inducible by the other. Inducibility therefore seems to be a property of the particular lysogenic strain and can be initiated by a variety of agents. Ionesco (1951) and Jacob (1952 $b$ ) showed that inducibility is a property of the prophage or the prophage-host cell complex and not of the particular bacterial strain which carries the prophage.

A similar parallelism was noted between the action of $U V$ radiation and phagolessin A58 on free phage particles (Hall \& Asheshov, 1953). Treatment 
of free phage particles with phagolessin A58 resulted in a loss of infectivity, but the inactivated particles remained capable of being adsorbing to and killing sensitive host organisms. These results with free phage particles suggest that the action of phagolessin A58 is directed against the nucleic acid of the particle rather than the protein fraction, since it has been shown (Herriott, 1951) that it is the protein fraction which is responsible for adsorption to and killing of sensitive host organisms. Further support to this theory is lent by the fact that DNA specifically inhibits the action of phagolessin A58 on free phage particles. DNA also inhibits the inducing action of phagolessin A58 and it is tempting to speculate that, in this instance, the site of action is the DNA of the lysogenic cell.

Weigle \& Delbrück (1951) suggested that the inducibility of a lysogenic strain might depend on the susceptibility of the carried phage to the inducing agent. With Escherichia coli strain K-12 they showed that this organism, which is inducible by UV radiation, carries a phage which is unusually resistant to UV radiation; Jacob (1954) reported similar results with lysogenic strains of Pseudomonas aeruginosa (pyocyanea). Induction of lysogenic strains by phagolessin A 58 is independent of the sensitivity of the carried phage to the antibiotic. Of the phages carried by the four different lysogenic strains used in the present work, phage 899 is the most sensitive and phage $\mathbf{F C b}$ the least sensitive to inactivation, yet both of these lysogenic strains are inducible by phagolessin A58. On the other hand, phage Temple and phage Lampert, lying midway between the other two phages with regard to their sensitivity to phagolessin A58, are carried by two non-inducible strains. Jacob (1952b) and Lwoff (1953) have both pointed out that inducible lysogenic strains are those strains which have a higher probability of undergoing spontaneous lysis. Our results are in agreement with this, since both Bacillus megaterium 899 and Escherichia coli $\mathrm{FCb}$ show a greater probability of lysing spontaneously than either of the other two strains, judging by the amount of free phage present in actively growing broth cultures of the four strains.

The authors are members of the Medical Research Council's external scientific staff.

\section{REFERENCES}

Asheshov, I. N. (1941). Papain digest and standardization of media in general. Canad. publ. Hith J. 32, 468.

Asheshov, I. N. \& Heagy, F. C. (1951). A 'loop' method for counting viable bacteria or bacteriophages. Canad. J. med. Sci. 29, 1.

Asheshov, I. N., Strelitz, F. \& Hall, E. A. (1952). Phagolessin A58: a new antibiotic active against bacterial viruses. Antibiot. \& Chemother. 2, 366.

Bertani, G. (1951). Studies on lysogenesis. I. The mode of phage liberation by lysogenic Escherichia coli. J. Bact. 62, 293.

Clarke, N. A. (1952). Studies on the host-virus relationship in a lysogenic strain of Bacillus megatherium. II. The growth of Bacillus megatherium in synthetic medium. J. Bact. 63, 187.

Den Dooren de Jong, L. E. (1930). The bacteriophages of Bacillus megatherium. Versl. gewone Vergad. Akad. Amst. 33, 51. 
Hall, E. A. \& Asheshov, I. N. (1953). A study of the action of phagolessin A58 on the T phages. J. gen. Physiol. 37, 217.

HerriotT, R. M. (1951). Nucleic acid free T2 virus 'ghosts' with specific biological action. J. Bact. 61, 752.

Ionesco, H. (1951). Systèmes inductible et non inductible chez Bacillus megatherium lysogène. C.R. Acad. Sci., Paris, 233, 1702.

$\mathrm{J}_{\mathrm{ACOB}}$, F. (1950). Induction de la lyse et de la production des bactériophages chez un Pseudomonas pyocyanea lysogène. C.R. Acad. Sci., Paris, 231, 1585.

$\mathrm{J}_{\mathrm{ACOB}}, \mathrm{F}$. (1952a). Production de bactériophages par action de la méthyl-bis(chloroéthyl) amine sur les bactéries lysogènes. C.R. Acad. Sci., Paris, 234, 2238.

$\mathrm{J}_{\mathrm{ACOB}}, \mathrm{F}$. (1952b). Développement spontané et induit des bactériophages chez des Pseudomonas pyocyanea polylysogènes. Ann. Inst. Pasteur, 83, 671.

$\mathrm{J}_{\mathrm{ACOB}}$, F. (1954). Les bactéries lysogènes et la notion de provirus. Paris: Masson et Cie.

Lwoff, A. (1953). Lysogeny. Bact. Rev. 17, 269.

Lwoff, A. \& Gutmann, A. (1950). Recherches sur un Bacillus megatherium. Ann. Inst. Pasteur, 78, 711.

LwoFf, A. \& J $\mathrm{J}_{\mathrm{ACOB}}, \mathrm{F}$. (1952). Induction de la production de bactériophage et d'une colicine par les peroxydes, les éthylèneimines et leshalogénoalcoylamines. C.R. Acad. Sci., Paris, 234, 2308.

Lwoff, A. \& Simonovitch, L. (1952). L'induction du développement du prophage par les substances réductrices. Ann. Inst. Pasteur, 82, 676.

Lwoff, A., Simonovitch, L. \& KJeldgaARd, N. (1950). Induction de la production de bactériophages chez une bactérie lysogène. Ann. Inst. Pasteur, 79, 815.

WAHL, R. (1946). Dissociation du Bacillus megatherium. Role de la composition du milieu. Action du bactériophages sur les variantes. Ann. Inst. Pasteur, 72, 473.

Weigle, J. J. \& Delbrück, M. (1951). Mutual exclusion between an infecting phage and a carried phage. J. Bact. 62, 301.

Williams Smith, H. (1953). The effect of physical and chemical changes on the liberation of phage particles by lysogenic strains of Salmonella. J. gen. Microbiol. 8, 116. 